\section{RMD Open}

Rheumatic \& Musculoskeletal Diseases

\title{
Trends of lymphoma incidence in US veterans with rheumatoid arthritis, 2002-2017
}

Namrata Singh (DD, ${ }^{1}$ Yubo Gao, ${ }^{2,3}$ Elizabeth Field, ${ }^{2,4}$ Brian K Link, ${ }^{5}$ Noel Weiss, ${ }^{6}$ Jeffrey R Curtis, ${ }^{7}$ Charles F Lynch, ${ }^{8}$ Mary Vaughan-Sarrazin ${ }^{3,4}$

To cite: Singh N, Gao Y, Field E, et al. Trends of lymphoma incidence in US veterans with rheumatoid arthritis, 2002-2017. RMD Open 2020;0: e001241. doi:10.1136/ rmdopen-2020-001241

Received 12 March 2020 Revised 12 May 2020 Accepted 17 June 2020
Check for updates

(C) Author(s) (or their employer(s)) 2020. Re-use permitted under CC BY-NC. No commercial re-use. See rights and permissions. Published by BMJ.

For numbered affiliations see end of article.

Correspondence to Namrata Singh; nasingh@medi cine.washington.edu

\section{ABSTRACT}

Objective Past epidemiological studies have consistently demonstrated a link between rheumatoid arthritis (RA) and the incidence of lymphoma and it has been posited that high systemic inflammatory activity is a major risk determinant of lymphomagenesis. Given advances in the therapeutic armamentarium for RA management in recent years, the resulting lower level of disease activity could have led to a decline in lymphoma incidence in patients with RA. This study examined recent trends in lymphoma incidence in US veterans with RA.

Methods Patients with RA were identified in the Veterans Affairs (VA) Corporate Data Warehouse. Lymphoma incidence was identified through the end of 2018 from the VA Central Cancer Registry and compared among patients diagnosed during 2003-2005, 2006-2008, 2009-2011 and 2012-2014.

Results Among persons diagnosed with RA during 2003-2005, the incidence of lymphoma in the next 6 years was 2.0 per 1000 person-years. There was a steady decline in lymphoma incidence during the corresponding 6 years following diagnosis in the subsequent three cohorts, with a rate of 1.5 per 1000 person-years in the 2012-2014 cohort (incidence relative to that in the 2003-2005 cohort $=0.79$ (95\% $\mathrm{Cl} 0.58$ to 1.1)). There was no similar decline in lymphoma incidence in VA patients diagnosed with osteoarthritis.

Conclusion We observed a decline in lymphoma incidence in recent years among American veterans with RA. Further studies are needed to evaluate the specific factors driving this decline.

\section{INTRODUCTION}

Collectively, lymphoid neoplasms are the fourth most common cancer and the sixth leading cause of cancer death in the USA. Epidemiological studies over the past decades have consistently demonstrated a link between rheumatoid arthritis (RA) and lymphomas, the association being strong for both non-Hodgkin lymphoma (NHL) and Hodgkin lymphoma (HL). ${ }^{1}{ }^{2}$ Mellemkjaer et al reported a relative risk (RR) of 1.7 (95\% CI 1.5 to 2) for all lymphatic and haematopoietic cancers in patients with RA, RR of 2.4 for NHL and RR of 3.4 for HL. ${ }^{3}$ There has been an

\section{Key messages}

What is already known about this subject?

- It is known that the patients with rheumatoid arthritis (RA) have a higher risk of lymphoma than the general population and that this risk is primarily mediated by the disease activity of RA.

What does this study add?

- To date, there is limited evaluation of the trends in lymphoma incidence in patientswith contemporary rheumatoid arthritis (RA).

- Our study observed a decline in lymphoma incidence inrecent years among patients with RA, but not among patientswith osteoarthritis.

How might this impact on clinical practice?

- Further studies looking at specific factors associated with the declining lymphoma incidence rates in patients with RA are needed.

ongoing concern regarding whether the elevated risk is from use of immunosuppressive therapies, particularly biologics like tumour necrosis factor inhibitors (TNFi). ${ }^{4}$ Recent observational studies with varied study settings and designs have not found the risk for lymphoma to be increased by the use of TNFi agents. $^{5}{ }^{6}$ In the largest case-control study reported to date with 378 Swedish patients with RA with lymphoma and 378 controls, Baecklund $e t a l^{7}$ concluded that 'high inflammatory activity, rather than its treatment, is a major risk determinant' for lymphoma. Patients with RA with the high cumulative disease activity had nearly a 60-fold increased risk of lymphoma compared with patients with low disease activity.

The management of RA has dramatically improved over the years since the introduction of the first TNFi agent in November 1998 and the subsequent approval of other potent biologic or conventional synthetic disease-modifying antirheumatic drugs (bDMARDs, csDMARDs). ${ }^{8}$ In 2010, an international expert consensus panel published treatment recommendations 
for $\mathrm{RA}^{9}$ that emphasised a treat-to-target (T2T) strategy of individualising and escalating treatment to achieve the lowest disease activity or remission in patients with RA. Studies from the Dutch Rheumatoid Arthritis Monitoring Remission Induction Cohort showed that implementation of T2T strategy in daily clinical practice for very early RA led to a high frequency of remission that was sustained in the majority of subjects. ${ }^{10}$ Early diagnosis and treatment with csDMARDs (eg, methotrexate) and subsequently with other bDMARDs (eg, inhibitors of tumour necrosis factor, interleukin 6) improve patient outcomes and prevent RArelated disability. ${ }^{10}{ }^{11}$ Meanwhile, the treatment for osteoarthritis (OA) has not evolved in recent years. Taking into consideration the improvement in RA treatment options and the evolution of RA treatment strategies, we hypothesised that incidence rates of lymphoma in patients with RA have declined over more recent years but not in patients with OA. With respect to lymphoma incidence, patients with OA are likely to represent the general population because of the minimally inflammatory nature of this condition for which care is typically sought.

\section{METHODS}

This study used data gathered during routine care to identify a cohort of patients with a diagnosis of RA and a comparison group of patients with OA, who received care through the nationwide Veterans Health Administration (VHA) healthcare network. Identification of patients and all analyses were performed through the Veterans Affairs (VA) Informatics and Computing Infrastructure (VINCI), an integrated infrastructure system from VHA's electronic medical records.

Patients: We identified patients with RA diagnosed from 1 January 2003 and 31 December 2017 using the VA Corporate Data Warehouse (CDW) on VINCI based on the following inclusion criteria: (1) adults $>18$ years of age with two or more RA diagnostic codes (International Classification of diseases (ICD) 9 (714.XX) or ICD10 $(\mathrm{M} 05 . \mathrm{XX}, \mathrm{M} 06 . \mathrm{XX}))$ at least 6 months apart during 2002-2017, with at least one visit in a rheumatology clinic; (2) no history of other autoimmune diseases associated with lymphoma (eg, Sjögren's syndrome, inflammatory bowel disease, celiac disease), based on diagnoses during the 12 months prior to RA diagnosis; and (3) no history of lymphoma diagnosis within 6 months after the first diagnosis of RA in the VA health system.

Patients with OA: Patients with OA were identified based on similar criteria as the RA cohort: adults $>18$ years of age with a diagnosis coded as ICD 9 (715.XX) and ICD 10 (M15-M19) at least twice within 1 year; at least 1 VA encounter 12 or more months prior to OA diagnosis; and no history of autoimmune diseases or lymphoma in the prior 12 months. For each patient with RA, up to two patients with $\mathrm{OA}$ were selected, with frequency matching based on initial year of RA or OA diagnosis (categorised as 2003-2005, 2006-2008, 2009-2011, 2012-2014), age (<55,
55-64, 65-74, and $\geq 75$ years old), sex, race (non-Hispanic white, non-Hispanic black, other non-white, missing) and number of VA primary care clinic visits during the 12 months prior to initial RA or OA diagnosis (categorised as $1,2-4,5-7,8+)$. For each patient, the 'index date' was defined as the date of the initial RA or OA diagnosis.

Outcomes: Our primary outcome was lymphoma incidence (ICD9 codes 200.x- 202.x and ICD10 C81-85.x) ${ }^{12}$ through 31 December 2018. The date of the first lymphoma diagnosis required at least a 6-month interval after the date of initial RA or OA diagnosis. Lymphomas are a heterogeneous group of diseases that can be classified into two broad subtypes: HL and NHL. Due to small numbers of cases in each sub-type of NHL or HL, we chose to restrict our evaluation to these two major types. The VINCI Cancer Module derived from the VA Central Cancer Registry (VACCR), a cancer registry that contains information on newly diagnosed cancers at the VA from 1995 onwards, was used for cancer identification. ${ }^{13}$ The VACCR has served as the gold standard of cancer ascertainment for the last decade ${ }^{14}$ where cancer registrars at the VA manually abstract case data, conforming to the standards set by the North American Association of Central Cancer Registries (NAACCR). ${ }^{13}$

Statistical analysis: Since RA diagnosis is a predictor of risk of malignant lymphoma, ${ }^{15}$ we analysed time trends in the incidence of lymphoma in the two groups of patients using a follow-up period limited to 6 years after the index dates. In a sensitivity analysis, we evaluated the trends with maximum follow-up truncated to 3 years, given that in the 6-year analysis, some members of the most recent year-ofdiagnosis cohort (2012-2014) did not have the full 6 years of follow-up.

Proportional hazards regression was used in which the dependent variable was the number of days between the index date and date of first lymphoma diagnosis (for patients with lymphoma), or the number of days between the index date and first censoring event (for patients without lymphoma). Censoring events included development of lymphoma (if applicable), death (from the VA Vital Status file) or end of the follow-up period (31 December 2018). For analysis of lymphoma subtypes, we also used Pearson product-moment correlation to measure the strength of association between the lymphoma incidence/1000 patient-years and categorised time intervals, as well as linear regression to fit the trend in lymphoma incidence over time.

\section{RESULTS}

We identified 43776 VA patients with RA meeting our eligibility criteria and 79772 eligible, matched patients with OA. Patient characteristics for these two cohorts were similar, as expected from the matching protocol (table 1). Twenty-five per cent of the patients in each group were aged $<55$ years and $61 \%$ were between 55 and 74 years. Ninety per cent of patients with OA were male and $76 \%$ 
Table 1 Baseline patient characteristics after frequency matching

\begin{tabular}{|c|c|c|}
\hline & $\begin{array}{l}\text { OA } \\
(n=79772)\end{array}$ & $\begin{array}{l}\text { RA } \\
(n=43776)\end{array}$ \\
\hline Males, $\mathrm{n}(\%)$ & $71680(90)$ & $38531(88)$ \\
\hline \multicolumn{3}{|l|}{ Age category, n (\%) } \\
\hline Less than 55 years & $20145(25)$ & $10814(25)$ \\
\hline $55-64$ years & $30088(38)$ & $16259(37)$ \\
\hline $65-74$ years & $18049(23)$ & $10719(24)$ \\
\hline 75 years and older & $11490(14)$ & $5984(14)$ \\
\hline \multicolumn{3}{|l|}{ Race/Ethnicity, n (\%) } \\
\hline Non-Hispanic white & $60930(76)$ & $33575(77)$ \\
\hline Black & $12585(16)$ & $66704(15)$ \\
\hline Other non-white & $3136(4)$ & $1768(4)$ \\
\hline Missing & $3121(4)$ & $1729(4)$ \\
\hline \multicolumn{3}{|c|}{$\begin{array}{l}\text { VA primary care visits during year } \\
\text { prior to diagnosis, } \mathrm{n}(\%)\end{array}$} \\
\hline $0-1$ & 26350 (33) & $13175(30)$ \\
\hline $2-4$ & $23958(30)$ & $14984(34)$ \\
\hline $5-7$ & $14661(18)$ & $7881(18)$ \\
\hline $8+$ & $14803(19)$ & $7736(18)$ \\
\hline \multicolumn{3}{|c|}{$\begin{array}{l}\text { Year of first diagnosis in VA } \\
\text { system, }{ }^{*}(\%)\end{array}$} \\
\hline $2003-2005$ & $18193(23)$ & 9457 (22) \\
\hline $2006-2008$ & $15290(19)$ & $8327(19)$ \\
\hline 2009-2011 & $17367(21)$ & $9483(22)$ \\
\hline 2012-2014 & $16504(21)$ & $9263(21)$ \\
\hline 2015-2017 & $12418(16)$ & $7246(16)$ \\
\hline
\end{tabular}

${ }^{*}$ As available in the study data used for the analysis.

OA, osteoarthritis; RA, rheumatoid arthritis; VA, Veterans Affairs.

were non-Hispanic white. Among patients with RA, $88 \%$ were men and $77 \%$ were non-Hispanic white.

In our primary analysis that limited follow-up to 6 years since diagnosis for each cohort, there were 417 lymphomas in OA group and 347 in the RA cohort (table 2), with a mean follow-up duration of 4.5 and 4.7 years, respectively. Among patients with RA, there was a steady decline in lymphoma incidence during the period of study. The incidence among patients diagnosed with RA during 2012-2014 was 1.5 per 1000 personyears, whereas among patients diagnosed in 2003-2005, it was 2.0 per 1000 person-years (table 2),
Table 3 Incidence of lymphoma among patients with RA or OA diagnosed in 2006-2008, 2009-2011 or 2012-2014 relative to that among patients diagnosed in 2003-2005, within the first 6 years of follow-up

\begin{tabular}{lll}
\hline & $\begin{array}{l}\text { RA } \\
\text { HR (95\% Cl; } \\
\text { p value) }\end{array}$ & $\begin{array}{l}\text { OA } \\
\text { HR (95\% Cl; } \\
\text { p value) }\end{array}$ \\
\hline $2006-2008$ vs & $0.87(0.65-1.2 ;$ & $0.88(0.7-1.2 ;$ \\
$2003-2005$ & $0.34)$ & $0.37)$ \\
$2009-2011$ vs & $0.81(0.58-1.09 ;$ & $0.98(0.76-1.3 ;$ \\
$2003-2005$ & $0.14)$ & $0.88)$ \\
$2012-2014$ vs & $0.79(0.58-1.09 ;$ & $1.07(0.8-1.4 ;$ \\
$2003-2005$ & $0.15)$ & $0.65)$ \\
\hline
\end{tabular}

OA, osteoarthritis; RA, rheumatoid arthritis.

corresponding to an HR of 0.79 (95\% CI 0.58 to 1.1 ) (table 3). Among patients with OA, there was no trend in the lymphoma incidence during the same period of time (tables 2 and 3 ).

In a sensitivity analysis in which the follow-up for each cohort was truncated to a maximum of 3 years (so that the maximum duration of follow-up was the same for all yearof-diagnosis cohorts), there were 175 lymphomas in patients with RA between 2003 and 2014 and 197 among the matched patients with OA. There were two lymphomas per 1000 patient-years in patients with RA diagnosed in 2003-2005 compared to 1.6 per 1000 patient-years in 2012-2014.

We then examined the incidence of HL and NHL among patients diagnosed with RA (shown in table 4) and OA (data not shown) in 2003-2014. Relative to patients with RA diagnosed in 2003-2005, those diagnosed in 2012-2014 had lower risk for NHL (HR 0.72, $85 \%$ CI 0.54 to $0.96, p=0.03)$. The rate of decline in the incidence of NHL was $0.56 / 1000$ per year for patients with RA $(\mathrm{p}=0.014)$ but unchanged for patients with OA $(\mathrm{p}=0.96)$ over the study time period (figure 1)

\section{DISCUSSION}

During the first decade and a half of the 21st century, those VA patients with RA who were more recently diagnosed experienced a lower subsequent incidence of

Table 2 Lymphoma incidence based on year of RA or OA diagnosis with maximum follow-up of 6 years since diagnosis

\begin{tabular}{|c|c|c|c|c|c|}
\hline $\begin{array}{l}\text { Disease type } \\
\text { and cohort year }\end{array}$ & $\begin{array}{l}\text { Patient-years }(n) / \\
\text { Lymphomas }(n=337)\end{array}$ & $\begin{array}{l}\text { Rate per } 1000 \\
\text { patient-years }\end{array}$ & $\begin{array}{l}\text { Disease type } \\
\text { and cohort year }\end{array}$ & $\begin{array}{l}\text { Patient-years }(n) / \\
\text { Lymphomas }(n=396)\end{array}$ & $\begin{array}{l}\text { Rate per } 1000 \\
\text { patient-years }\end{array}$ \\
\hline RA 2003-2005 & 52 987/107 & 2 & OA 2003-2005 & $97931 / 117$ & 1.2 \\
\hline RA 2006-2008 & $46661 / 82$ & 1.8 & OA 2006-2008 & $81717 / 86$ & 1.1 \\
\hline RA 2009-2011 & 53 244/87 & 1.6 & OA 2009-2011 & 93 087/109 & 1.2 \\
\hline RA 2012-2014 & 39 529/61 & 1.5 & OA 2012-2014 & 68 160/84 & 1.2 \\
\hline
\end{tabular}

Not shown: For the 2015-2017 cohorts, 10 and 21 lymphomas were diagnosed in patients with RA and OA patients, respectively.

$\mathrm{OA}$, osteoarthritis; RA, rheumatoid arthritis. 
Table 4 Incidence of Hodgkin and non-Hodgkin lymphoma based on year of RA diagnosis with maximum follow-up of 6 years since diagnosis

\begin{tabular}{lll}
\hline $\begin{array}{l}\text { Disease type } \\
\text { and cohort year }\end{array}$ & $\begin{array}{l}\text { Patients (n)/ } \\
\text { Hodgkin lymphoma } \\
\text { (n) }\end{array}$ & $\begin{array}{l}\text { Rate per 1000 } \\
\text { patient-years }\end{array}$ \\
\hline \multicolumn{2}{l}{ Hodgkin lymphoma } & \\
RA 2003-2005 & $9457 / 18$ & 0.34 \\
RA 2006-2008 & $8327 / 12$ & 0.26 \\
RA 2009-2011 & $9483 / 11$ & 0.21 \\
RA 2012-2014 & $9263 / 12$ & 0.30 \\
Non-Hodgkin & Patients (n)/non- & Rate per 1000 \\
lymphoma & Hodgkin ymphoma (n) & patient-years \\
RA 2003-2005 & $9457 / 95$ & 1.79 \\
RA 2006-2008 & $8327 / 72$ & 1.54 \\
RA 2009-2011 & $9483 / 76$ & 1.43 \\
RA 2012-2014 & $9263 / 50$ & 1.27 \\
\hline
\end{tabular}

$R A$, rheumatoid arthritis.

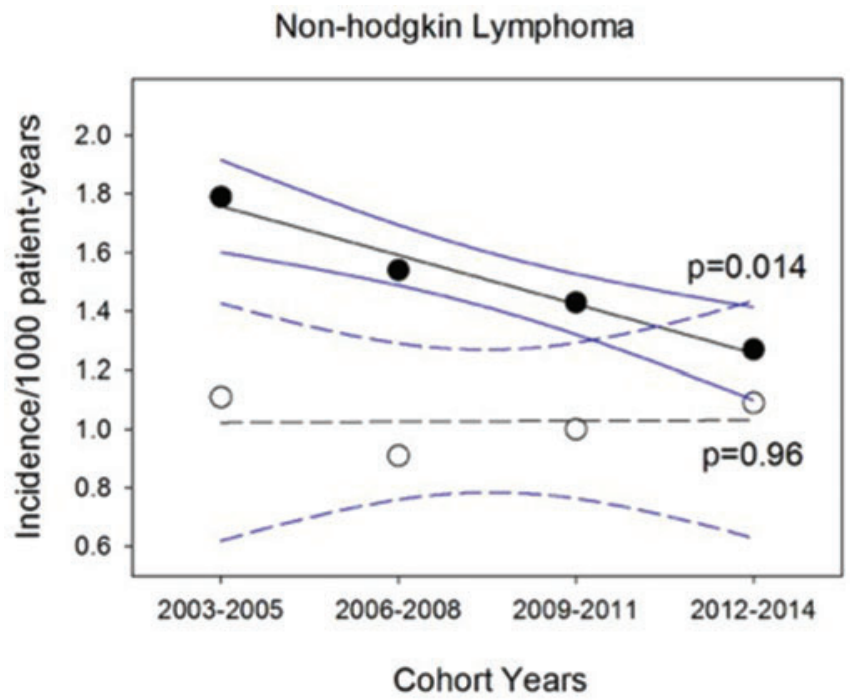

Figure 1 Incidence of non-Hodgkin lymphoma in RA and OA. The incidence of non-Hodgkin lymphoma decreased over 2003-2014 timespan for subjects with RA (•, p=0.014, Pearson correlation) but not $\mathrm{OA}(\mathrm{O}, \mathrm{p}=0.96$, Pearson correlation). Figure shows linear regression (black) and 95\% confidence band (blue) for RA (solid, $R^{2}=0.97$ ) and OA (dashed, $R^{2}=0.002$ ) subjects. OA, osteoarthritis; RA, rheumatoid arthritis.

lymphoma than those diagnosed in earlier years. During this same time period, there was no corresponding decline in lymphoma incidence in patients with OA. The declining rate appeared to be largely driven by a decreasing incidence of NHL; the numbers for other lymphoma subtypes (eg, HL, follicular lymphoma) were too small to draw meaningful conclusions about trends in their incidence.
In Swedish patients with RA diagnosed between 2004 and 2012, the risk of lymphoma was not lower than in patients with RA diagnosed in 1997-2003. ${ }^{16}$ There are several factors that can potentially explain the observed differences in our results. Of importance, our study extends the ascertainment of lymphoma incidence through 2017, whereas Hellgren et al studied patients with RA up to 2012 only. The two cohorts of patients with RA were also different demographically, as our VA cohort was predominantly male with some racial diversity compared to patients in the Swedish Rheumatology Quality register (approximately $70 \%$ female and nearly all white).

Given that systemic inflammation has been postulated to be a strong risk factor for lymphomagenesis in RA, ${ }^{7} 17$ we speculate that the declining lymphoma incidence in RA might be related to better disease control by early and intensive treatments in recent years. $\mathrm{Ng}$ et al evaluated trends in the use of DMARDs in patients with RA in the VA medical system and found that use of methotrexate as the first DMARD increased from $39.9 \%$ in 1999-2001 to $57.2 \%$ in $2008-2009(\mathrm{p}<0.001) .{ }^{18}$ They also showed that patients with RA diagnosed in 2008-2009 had a 74\% higher chance of an earlier start on biologics than those diagnosed in 1999-2001 and that the time interval between RA diagnosis and treatment with DMARDs and biological agents decreased over time (median: 51 days in 1999-2001 to 28 days in 2006-2007). In a more recent evaluation, Walsh et al found that the percentage of RA veterans receiving DMARD treatment (non-biologic or biologic) increased between 2007 and 2015 (50.4\% (95\% CI 47.5 to 53.2 ) to $68.6 \%$ (95\% CI 65.6 to 71.4)). ${ }^{19}$ Also, the possible contribution of direct lymphoma suppression-as opposed to indirect suppression via reduced inflammatory biology — with use of anti-CD20 monoclonal antibody such as rituximab could be another possible explanation that requires further exploration.

There have been several studies evaluating the association between immunosuppressive medications used for RA treatment and the lymphoma incidence. Baecklund et al observed a reduction in lymphoma incidence among persons who were given oral steroids (OR 0.6 ()) and intraarticular steroids (OR 0.4 (95\% CI 0.2 to 0.6) ), after adjustment for disease activity and DMARD use. ${ }^{7}$ They further observed that a total duration of oral steroid treatment of $<2$ years was not associated with lymphoma risk (OR $0.87,95 \%$ CI 0.51 to 1.5 ), whereas total treatment $>2$ years was associated with a lower lymphoma risk (OR $0.43,95 \%$ CI 0.26 to 0.72 ) ${ }^{20}$ Several studies have not found an increased risk of NHL in methotrexate-treated patients with $\mathrm{RA},{ }^{21}{ }^{22}$ whereas Mariette et al found an increased risk of HL, but not NHL, in a prospective 3-year study of methotrexatetreated French patients with RA compared to the general population. ${ }^{23}$

Even though TNFi have been a topic of scrutiny regarding lymphoma, most of the evidence in multiple large robust registry-based studies from different countries, 
including Sweden, the USA and the UK, suggest that the risk of lymphoma is not increased in TNFi users compared to patients with RA on csDMARDs. ${ }^{6} 1624$ Mercer et al recently reported results from a large collaborative effort of multiple European registries, including $>120000$ patients with RA, and found no evidence of any modification of the distribution of lymphoma subtypes in patients with RA treated with TNFi compared with bionaive patients. ${ }^{25}$ Data regarding some of the newer bDMARDs and targeted synthetic DMARDs (tsDMARDs) like baricitinib are currently limited. There remains a need for studies evaluating the safety of multiple bDMARDs, and especially, the tsDMARDs.

The strengths of this study include use of the large national VA database, use of the VACCR for identifying lymphoma cases and longitudinal follow-up. Having a large cohort of patients with RA allowed us to look at the trends of a relatively rare outcome like lymphoma. The VACCR strives to maintain the NAACCR standards whereby the cancer registrars at VA medical facilities across the country abstract case data. If VA patient's cancer diagnosis is made outside the VA, VACCR will capture those cases as well if they subsequently receive care within the VA. ${ }^{13}$

One limitation of the study is the use of administrative codes-based algorithm for diagnosis of RA, and OA that introduces the possibility of misclassification bias. However, the algorithms we used have been shown to have high sensitivity and positive predictive value for RA. ${ }^{26}$ VACCR ascertains $\sim 90 \%$ of all VA cancers. We assume the missingness to be similar during the period of the study and so is unlikely to affect our results to any appreciable degree. Another limitation is that the most contemporary cohort (2012-2014) in the study did not have follow-up for the full 6 years. Given that the incidence of lymphoma rises with increasing time since RA diagnosis, this will lead to some confounding and will tend to exaggerate a reduction in incidence among that cohort. In addition, the need to restrict follow-up for lymphoma to the first 6 years following diagnosis forbids any conclusion regarding incidence in later years. Another consideration is the fact that many veterans enrolled in the VA also receive healthcare in other systems. Schwab et al have shown that most US veterans with RA who access VA care use the VA as their primary source of arthritis care and only $6 \%$ of dual care users in their study had non-VA haematologist/oncologists. ${ }^{27} \mathrm{We}$ did not adjust for disease activity or disease-modifying antirheumatic drugs use in these analyses. Finally, the relatively small number of women in our study population did not allow for a separate analysis to be performed in them and limit the generalisability of our results.

To conclude, we observed a trend towards reduced incidence of lymphoma among US veterans diagnosed with RA in recent years relative to those diagnosed in earlier years. Further studies looking at specific factors associated with the declining lymphoma incidence rates in patients with RA are needed.
Author affiliations

${ }^{1}$ Rheumatology, University of Washington, Seattle, Washington, USA

${ }^{2}$ Center for Comprehensive Access and Delivery Research and Evaluation, lowa City Veterans Affairs Health Care System, lowa City, lowa, USA

${ }^{3}$ Department of Internal Medicine, University of lowa Hospitals and Clinics, lowa City, Iowa, USA

${ }^{4}$ Division of Immunology, Department of Internal Medicine, The University of lowa, lowa City, lowa, USA

${ }^{5}$ University of lowa Roy $\mathrm{J}$ and Lucille A Carver College of Medicine, lowa City, lowa, USA

${ }^{6}$ Department of Epidemiology, University of Washington, Seattle, Washington, USA ${ }^{7}$ Division of Clinical Immunology and Rheumatology, University of Alabama at Birmingham, Birmingham, Alabama, USA

${ }^{8}$ Epidemiology, University of lowa College of Public Health, lowa City, lowa, USA

Contributors Concept, design and discussion of results and manuscript draft review: NS, CFL, EF, MV-S, NW and JRC. Cohort creation and data analysis: YG and MV-S.

Funding This work was funded by Grant IRG-15-176-41 from the American Cancer Society, administered through the Holden Comprehensive Cancer Center at The University of lowa. Dr Vaughan Sarrazin receives support from the VA Health Services Research \& Development Service.

Competing interests None declared.

Patient consent for publication Not required.

Ethics approval This study was approved by the lowa City VA Medical Center.

Provenance and peer review Not commissioned; externally peer reviewed.

Data availability statement All data relevant to the study are included in the article. Data availability is unfortunately not possible to protect patient confidentiality. Open access This is an open access article distributed in accordance with the Creative Commons Attribution Non Commercial (CC BY-NC 4.0) license, which permits others to distribute, remix, adapt, build upon this work non-commercially, and license their derivative works on different terms, provided the original work is properly cited, appropriate credit is given, any changes made indicated, and the use is non-commercial. See: http://creativecommons.org/licenses/by-nc/4.0/.

\section{ORCID iDs}

Namrata Singh http://orcid.org/0000-0001-7149-363X

\section{REFERENCES}

1 Baecklund E, Natkunam Y, Backlin C, et al. Expression of the human germinal-centre-associated lymphoma protein in diffuse large B-cell lymphomas in patients with rheumatoid arthritis. $\mathrm{Br} J$ Haematol 2008:141:69-72.

2 Simon TA, Thompson A, Gandhi KK, Suissa S, et al. Incidence of malignancy in adult patients with rheumatoid arthritis: a meta-analysis. Arthritis Res Ther 2015;17:212.

3 Mellemkjaer L, Linet MS, Gridley G, Olsen JH, et al. Rheumatoid arthritis and cancer risk. Eur J Cancer 1996;32A:1753-7.

4 Bongartz T, Sutton AJ, Sweeting MJ, Montori V, et al. Anti-TNF antibody therapy in rheumatoid arthritis and the risk of serious infections and malignancies: systematic review and meta-analysis of rare harmful effects in randomized controlled trials. JAMA 2006;295:2275-85.

5 Askling J, Baecklund E, Granath F, et al. Anti-tumour necrosis factor therapy in rheumatoid arthritis and risk of malignant lymphomas: relative risks and time trends in the Swedish biologics register. Ann Rheum Dis 2009;68:648-53.

6 Mercer LK, Galloway JB, Lunt M, Hyrich KL, et al. Risk of lymphoma in patients exposed to antitumour necrosis factor therapy: results from the British Society for Rheumatology Biologics Register for Rheumatoid Arthritis. Ann Rheum Dis 2017;76:497-503.

7 Baecklund E, lliadou A, Askling J, et al. Association of chronic inflammation, not its treatment, with increased lymphoma risk in rheumatoid arthritis. Arthritis Rheum 2006;54:692-701.

8 Smolen JS, Aletaha D, Barton A, et al. Rheumatoid arthritis. Nat Rev Dis Primers 2018;4:18001.

9 Smolen JS, Aletaha D, Bijlsma JW, et al. Treating rheumatoid arthritis to target: recommendations of an international task force. Ann Rheum Dis 2010;69:631-7.

10 Vermeer M, Kuper HH, Moens HJ, van de Laar MA, et al. Sustained beneficial effects of a protocolized treat-to-target strategy in very early 
rheumatoid arthritis: three-year results of the Dutch rheumatoid arthritis monitoring remission induction cohort. Arthritis Care Res (Hoboken) 2013;65:1219-26.

11 Greenberg JD, Kremer JM, Curtis JR, et al. Tumour necrosis factor antagonist use and associated risk reduction of cardiovascular events among patients with rheumatoid arthritis. Ann Rheum Dis 2011;70:576-82.

12 Herman RA, Gilchrist B, Link BK, Carnahan R. A systematic review of validated methods for identifying lymphoma using administrative data Pharmacoepidemiol Drug Saf 2012;21:203-12.

13 Zullig LL, Sims KJ, McNeil R, Kelley MJ, et al. Cancer incidence among patients of the U.S. veterans affairs health care system: 2010 update. Mil Med 2017;182:e1883-e1891.

14 Earles A, Liu L, Bustamante R, et al. Structured approach for evaluating strategies for cancer ascertainment using large-scale electronic health record data. JCO Clin Cancer Inform 2018;2:1-12.

15 Hellgren K, Smedby KE, Feltelius N, Askling J, et al. Do rheumatoid arthritis and lymphoma share risk factors?: a comparison of lymphoma and cancer risks before and after diagnosis of rheumatoid arthritis. Arthritis Rheum 2010;62:1252-8.

16 Hellgren K, Baecklund E, Backlin C, Askling J, et al. Rheumatoid arthritis and risk of malignant lymphoma: is the risk still increased? Arthritis Rheumatol 2017;69:700-8.

17 Baecklund E, Smedby KE, Sutton LA, Rosenquist R, et al. Lymphoma development in patients with autoimmune and inflammatory disorders: what are the driving forces? Semin Cancer Biol 2014;24:61-70.

$18 \mathrm{Ng} \mathrm{B}$, Chu A, Khan MM, Khan MM. A retrospective cohort study: 10-year trend of disease-modifying antirheumatic drugs and biological agents use in patients with rheumatoid arthritis at veteran affairs medical centers. BMJ Open 2013;3:4

19 Walsh JA, Pei S, Penmetsa GK, et al. Treatment patterns with disease-modifying antirheumatic drugs in U.S. Veterans with newly diagnosed rheumatoid arthritis, psoriatic arthritis, or ankylosing spondylitis. J Manag Care Spec Pharm 2019;25:121828.

20 Hellgren K, Iliadou A, Rosenquist R, Baecklund E, et al. Rheumatoid arthritis, treatment with corticosteroids and risk of malignant lymphomas: results from a case-control study. Ann Rheum Dis 2010;69:654-9.

21 Kremer JM. Safety, efficacy, and mortality in a long-term cohort of patients with rheumatoid arthritis taking methotrexate: followup after a mean of 13.3 years. Arthritis Rheum 1997;40:9845 .

22 Moder KG, Tefferi A, Cohen MD, Luthra HS, et al. Hematologic malignancies and the use of methotrexate in rheumatoid arthritis: a retrospective study. Am J Med 1995;99:276-81.

23 Mariette X, Cazals-Hatem D, Warszawki J, et al. Investigators of the Club Rhumatismes et Inflammatio. Lymphomas in rheumatoid arthritis patients treated with methotrexate: a 3-year prospective study in France. Blood 2002;99:3909-15.

24 Wolfe F, Michaud K, Michaud K. The effect of methotrexate and anti-tumor necrosis factor therapy on the risk of lymphoma in rheumatoid arthritis in 19,562 patients during 89,710 person-years of observation. Arthritis Rheum 2007;56:1433-9.

25 Mercer LK, Regierer AC, Mariette X, et al. Spectrum of lymphomas across different drug treatment groups in rheumatoid arthritis: a European registries collaborative project. Ann Rheum Dis 2017;76:2025-30.

26 Singh JA, Holmgren AR, Noorbaloochi S, Noorbaloochi S. Accuracy of veterans administration databases for a diagnosis of rheumatoid arthritis. Arthritis Rheum 2004;51:952-7.

27 Schwab P, Sayles H, Bergman D, Barton J, et al. Utilization of care outside the veterans affairs health care system by US veterans with rheumatoid arthritis. Arthritis Care Res (Hoboken) 2017;69:776-82. 